\title{
ESTIMATION OF YIELD AND YIELD STABILITY OF SPRING BARLEY GENOTYPE MIXTURES
}

\author{
Indra Ločmele, Linda Legzdiņa, Zinta Gaile, Arta Kronberga \\ Latvia University of Agriculture \\ indra.locmele@1lu.lv
}

\begin{abstract}
Organic farmers need varieties adapted to variable growing conditions, because in organic farms environmental conditions significantly vary in soil nutrient status, weed and disease pressure not only between years, but also among farms within a season. Modern varieties developed under high input agricultural systems do not always perform well under organic growing conditions. Therefore, farmers need such varieties of cereals that can adapt to variable growing conditions and maintain productivity. One of the ways to promote adaptation to environment is growing of variety mixtures. Field trials were conducted during 2014-2016 under organic and conventional farming systems in two locations with an aim to estimate the advantages of barley mixtures in respect of yield and its stability. The trial consisted of eight mixtures of barley varieties and breeding lines, components of mixtures in pure stand and three check varieties. The mixtures were combined by using two, three and five components. Three mixtures, each in one out of 11 environments significantly out-yielded, but one mixture had significantly lower yield than the average value of their components. Some mixtures showed a tendency to out-yield the average of components in both farming systems. All mixtures insignificantly out-yielded check varieties in 2015, but in 2016, yield was within the range between varieties with lowest and highest yield. The results of yield stability analysis showed that mixtures could be used as one of the approaches to stabilize yield - only one of eight mixtures had a lower yield than the average over all environments.
\end{abstract}

Key words: variety mixtures, yield, yield stability.

\section{Introduction}

Modern high yielding varieties are usually grown under high input agricultural systems, but they generally do not perform well under low-input situations (Fess, Kotchon, \& Beneditto, 2011). Plant breeders have achieved high yield through hybridization and selection of superior plants. In hybridization often are included only new and most productive varieties. The result of this approach is reduction of genetic diversity and the loss of ability to adapt to variable environments. Due to development of organic agriculture in the last decades, the importance of appropriate varietal choice is increasing (Wolfe et al., 2008). In organic farms, the growing conditions significantly vary in soil nutrient status and weed, pest and disease pressure not only between years, but within seasons among farms, too. Therefore, such varieties of cereals are necessary that can adapt to variable growing conditions and maintain productivity. This can be achieved via extended genetic diversity of plants within the varieties. Increasing genetic diversity in crops could ensure yield stability and adaptability, reduce disease distribution and improve competitive ability with weeds and nutrient uptake efficiency (Döring et al., 2011). Development of crop varieties requires large inputs of material, financial and time resources, therefore one of the ways to add genetic diversity at the shortest time and cheaper is by growing variety mixtures (Lopez \& Mundt, 2000). It is not possible to predict which mixture component will provide advantage in the respective year and environment while sowing mixtures, but compensation mechanism can provide stability (Kaut et al., 2009).

Mixtures of varieties with different characteristics have proved to be means of increasing, as well as stabilizing the yield in terms of various aspects: morphological and phenological differences of plants (Jedel, Hekm, \& Burnett, 1998) and ratio effects (Juskiw, Helm, \& Burnett, 2001), manner of seed mixing (Newton \& Guy, 2009), phenotypic contrasts (Essah \& Stoskop, 2002), soil tillage effects (Newton et al., 2012), manure application, root development, and growth rate (Askegaard et al., 2011). The effect of number of components in mixtures has been evaluated in several studies (Mille et al., 2006; Newton, Hacket, \& Swanson, 2008; Kaut et al., 2009), as well as possibilities to reduce levels of fungal disease by growing mixtures (Tratwal, Law, \& Philpott, 2007; Muchova \& Faekašova, 2010; Newton \& Guy, 2009; Newton et al., 2012). In some studies, the yield of mixtures has been about the same, or slightly higher or lower than the mean of their components, and positive effect of variety mixtures is seen on the yield stability. Further studies about the possibilities to increase yield and yield stability of the crop by increasing the genetic diversity are needed. It is essential to understand what plant traits are most important in the mixtures (Mille et al., 2006).

The aim of the research was to find out the efficiency of spring barley genotype mixtures in improving certain traits: yield and yield stability, competitive ability with weeds and infection severity with leaf diseases. The aim of the present paper is 
to estimate advantages of eight, two, three and fivecomponent spring barley mixtures in comparison to average value of the respective components in pure stand, and three check varieties.

\section{Materials and Methods}

The investigation was carried out at Institute of Agricultural Resources and Economics Priekuli Research Centre (latitude $57.3148^{\circ} \mathrm{N}$, longitude $25.3388^{\circ}$ E) and Stende Research Centre (latitude $57.1412^{\circ} \mathrm{N}$, longitude $22.5367^{\circ} \mathrm{E}$ ). Field trials were carried out during 2014 - 2016 in Priekuli and Stende under both conventional $(\mathrm{C})$ and organic $(\mathrm{O})$ growing conditions. The experimental design in 2014 was a randomized complete block, but in 2015 and 2016 lattice design (Petersen, 1994) with four replications. Plot size was $12.3 \mathrm{~m}^{2}$ in Priekuli and $5.2 \mathrm{~m}^{2}$ in Stende, seed rate 400 untreated germinable seeds per $\mathrm{m}^{2}$. Field trial in Stende under $\mathrm{O}$ growing conditions in 2015 was significantly damaged by heavy rainfall after sowing. Therefore, the results of 11 instead of planned 12 environments were obtained. Eight mixtures of barley (Hordeum vulgare L.) varieties and breeding lines were used in the study. The mixtures consisted of two, three and five components. Seed of mixtures was prepared every year by mixing components in equal proportions according to the germination ability. The genotypes used to compose mixtures varieties 'Rubiola', 'Vienna', 'Anni' and 13 local breeding lines - have characteristics which are highly important in organic farming (Table 1). One of the criteria of choosing components for mixtures was yield. Genotypes with a higher yield than the average level of previous field trials were selected. The yield of mixtures was compared to the average value of the respective components in pure stands in 11 testing sites $(2014-2016)$ and to three commercially used check varieties: 'Rubiola' - released for growing under organic conditions, 'Rasa' - check variety in official trials for testing of value for cultivation and use (VCU) under organic growing conditions, and 'Abava' - characterized as a variety with good adaptability to various environments in seven environments (2015 - 2016).

The soil in all locations was sod-podzolic sand loam (Kārkliņš, 2008). Other soil properties are summarized in Table 2

Pre-crop in all C environments was potatoes, except in Stende in 2014 it was annual ryegrass; in O locations pre-crop in Priekuli was green manure in 2014 and grain legumes in 2015 and 2016; in Stende - legumes, spring wheat and buckwheat,

\section{Characteristics of genotype mixtures}

Table 1

\begin{tabular}{|c|c|l|}
\hline Mixture & $\begin{array}{c}\text { Number of } \\
\text { components }\end{array}$ & \multicolumn{1}{|c|}{ Criteria for the selection of components for mixtures* } \\
\hline M 1, M 2 & 3 & Different adaptability to growing conditions \\
\hline M 3 & 3 & Different plant growth habit - erect, intermediate and planophyle \\
\hline M 4 & 5 & $\begin{array}{l}\text { Combination of rapid plant development, good soil covering ability, good tillering, } \\
\text { early heading, leaf bending }\end{array}$ \\
\hline M 5 & 2 & Different weed competitiveness \\
\hline M 6, M 8 & 3 & $\begin{array}{l}\text { Different level of infection with foliar diseases caused by Pyrenophora teres and } \\
\text { Blumeria graminis }\end{array}$ \\
\hline M 7 & 2 &
\end{tabular}

*According to the results of ESF co-financed project "Development, improvement and implementation of environmentally friendly and sustainable crop breeding technologies"

Soil agrochemical properties during 2014 - 2016

Table 2

\begin{tabular}{|c|c|c|c|c|c|c|c|c|c|c|c|}
\hline \multirow{3}{*}{ Properties } & \multicolumn{6}{|c|}{ Priekuli } & \multicolumn{5}{|c|}{ Stende } \\
\hline & \multicolumn{3}{|c|}{ conventional } & \multicolumn{3}{|c|}{ organic } & \multicolumn{3}{|c|}{ conventional } & \multicolumn{2}{|c|}{ organic } \\
\hline & 2014 & 2015 & 2016 & 2014 & 2015 & 2016 & 2014 & 2015 & 2016 & 2014 & 2016 \\
\hline $\mathrm{pH} \mathrm{KCL}$ & 5.5 & 5.8 & 5.5 & 5.8 & 5.7 & 5.7 & 6.6 & 5.9 & 6.1 & 5.9 & 6.0 \\
\hline $\begin{array}{l}\text { Organic matter } \\
\text { content, } \%\end{array}$ & 2.1 & 2.1 & 2.3 & 2.3 & 2.2 & 2.4 & 3.5 & 1.9 & 1.9 & 2.3 & 1.9 \\
\hline $\mathrm{K}_{2} \mathrm{O} \mathrm{mg} \mathrm{kg}{ }^{-1}$ & 149 & 176 & 136 & 128 & 135 & 175 & 116 & 176 & 168 & 180 & 115 \\
\hline $\mathrm{P}_{2} \mathrm{O}_{5} \mathrm{mg} \mathrm{kg}^{-1}$ & 172 & 125 & 143 & 182 & 169 & 163 & 246 & 219 & 219 & 265 & 151 \\
\hline
\end{tabular}


respectively. Before sowing, in $\mathrm{C}$ sites complex mineral fertilizer was applied ensuring the following amounts of pure elements: in Priekuli N 95-97, $\mathrm{P}_{2} \mathrm{O}_{5}$ 50-62, $\mathrm{K}_{2} \mathrm{O} 45-93$, in Stende $\mathrm{N} 75-80, \mathrm{P}_{2} \mathrm{O}_{5} 75-80$, $\mathrm{K}_{2} \mathrm{O} 75-80 \mathrm{~kg} \mathrm{ha}^{-1}$. In the plant tillering stage (GS 21 - 29), harrowing was performed in $\mathrm{O}$ growing sites with an aim to restrict weeds, but in $\mathrm{C}$ growing environments herbicide was applied.

The obtained data was analyzed by using single and two-factor analysis of variance. Regression of yield on environmental index (the difference between the average yield of all tested genotypes in a given environment and the average yield of all genotypes of all environments) was done to evaluate the yield stability. One of the indicators used to characterize yield stability was coefficient of regression (b). Genotypes with b larger than 1 were considered as responsive to high yielding environments; genotypes with $\mathrm{b}$ close to 1 - stable and with wide adaptability, and the ones with $b$ lower than 1 - with adaptability to low yielding environments. A variety was considered stable if its yield was at least at the level of average productivity, coefficient of regression was not significantly different from 1 , and deviation from regression $\left(s^{2} \mathrm{dj}\right)$ was as close as possible to zero (Eberhart \& Russel, 1966). Ranking method was used to obtain additional information about adaptability of mixtures to specific growing conditions - mixtures and its components in pure stand were ranked within sites, and scores given for top, middle and low level in the range for individual genotypes across sites were summarized (Fox et al., 1990).

Meteorological conditions during the investigation differed not only between the years, but also between the field trial locations. There was no precipitation in both growing locations in 2014 during sowing and the average air temperature exceeded the long-term data (hereinafter-norm). May and July was hit by a warmer and drier weather than the long-term data, except in Priekuli in May, where the precipitation exceeded the long-term data by $73 \%$. In June, there was heavy precipitation in both growing locations, going beyond the long-term data, while the air temperature during the third and second decade of the month was below the norm, which slightly delayed the development of the plants. There was increased rainfall and the air temperature was close to the norm in both locations in the third decade of April 2015. During the following growing season the average air temperature was below the long-term data in both locations, but precipitation exceeding the norm was observed only in May in Stende. The weather differed drastically in 2016, when in Priekuli, after experiencing an increased rainfall in the last decade of April, which delayed the sowing, in May fell $18 \%$ of the norm. There was increased rainfall starting with the second decade of June up to the end of August in Priekuli, peaking during the third decade of June, when it rained by $309 \%$ more than in the long-term data. During this decade, the weather was warmer than usual - air temperature was higher than the norm by $4.5^{\circ} \mathrm{C}$ in Priekuli and by $3.1^{\circ} \mathrm{C}$ in Stende. In 2016, annual precipitation resembled the long-term data in Stende, exceeding the norm only in June by $62 \%$. In general, meteorological conditions were more favorable for barley development in 2015 and in 2016 at both growing environments in Stende. Heavy precipitation in June 2014 and temperature below norm and dry conditions in May 2016 in Priekuli slightly delayed the development of the plants.

\section{Results and Discussion}

Yield of mixtures in comparison to average of the respective components

In all years of the study, the mixtures' yield was significantly affected both by the growing environment and genotype; as well as interaction between environment and genotype was significant ( $p$ $<0.01)$.

No significant differences between yield of variety mixtures and average value of respective components were observed in 2014. A significantly higher yield of mixtures in comparison to average of the respective mixture components was observed only under $\mathrm{C}$ growing conditions in 2015 for mixture M1 in Priekuli, and M7 and M8 in Stende $(\mathrm{p}<0.05)$ (Table 3). However, in 2016 under O conditions in Stende, mixture M6 produced a significantly lower yield than the average of components. It should be noted that the yield of mixture M7 increased in comparison with the average (at confidence level 95\% significant differences were not found) in eight (four $\mathrm{O}$ and four $\mathrm{C}$ ) out of eleven testing environments, which ranged $1-12 \%$ in $\mathrm{O}$ environments and $5-12 \%$ in $\mathrm{C}$ environments. In seven (four $\mathrm{O}$ and three $\mathrm{C}$ ) out of eleven testing environments, the yield increase was observed in mixtures M5 and M6. For mixture M5, it was $1-10 \%$ under $\mathrm{O}$ growing conditions and $2-$ $6 \%$ under $\mathrm{C}$ conditions, while for M6 the increase was $5-9 \%$ and $1-3 \%$, respectively. Yet, as mentioned above, in one case the yield of M6 was observed to be significantly lower than the average of components.

Mixture M7, which showed the largest yield increase in the most environments if compared to the average of respective components, was composed of two genotypes (Table 1). Another comparatively successful mixture M5 was also produced by using two genotypes. Possibly, this tendency shows that in two-component mixtures there is a lower competition between different plants, as it was also mentioned by Döring et al., (2011). In theory, under O growing conditions, where plants have to compete with weeds, less competition between different plants should 
Differences between yield of mixtures and average of its components, $t$ ha $^{-1}$

\begin{tabular}{|l|c|c|c|c|c|c|c|c|c|c|c|}
\hline & \multicolumn{4}{|c|}{2014} & \multicolumn{3}{c|}{2015} & \multicolumn{4}{c|}{2016} \\
\cline { 2 - 14 } & $\mathrm{P}^{* *} \mathrm{O} * * *$ & $\mathrm{~S} * * \mathrm{O}$ & $\mathrm{PC} * *$ & $\mathrm{SC}$ & $\mathrm{PO}$ & $\mathrm{PC}$ & $\mathrm{SC}$ & $\mathrm{PO}$ & $\mathrm{SO}$ & $\mathrm{PC}$ & $\mathrm{SC}$ \\
\hline M1 & -0.06 & 0.11 & 0.36 & -0.19 & -0.14 & $0.61^{*}$ & 0.43 & -0.20 & -0.29 & 0.33 & 0.37 \\
\hline M2 & -0.30 & 0.01 & 0.11 & 0.09 & 0.26 & 0.17 & -0.23 & -0.17 & 0.86 & 0.06 & -0.03 \\
\hline M3 & -0.12 & -0.11 & 0.25 & 0.31 & -0.11 & -0.03 & 0.01 & 0.41 & -0.04 & 0.13 & -0.41 \\
\hline M4 & 0.09 & 0.08 & 0.19 & -0.42 & 0.01 & -0.09 & 0.02 & -0.14 & -0.13 & -0.09 & 0.37 \\
\hline M5 & 0.07 & 0.29 & 0.08 & 0.17 & 0.09 & 0.00 & -0.15 & -0.16 & 0.05 & -0.01 & 0.43 \\
\hline M6 & 0.26 & 0.14 & -0.10 & -0.01 & 0.33 & 0.04 & 0.22 & 0.20 & $-0.56^{*}$ & 0.10 & -0.31 \\
\hline M7 & 0.04 & 0.27 & -0.11 & 0.24 & 0.45 & 0.49 & $0.77 *$ & 0.31 & -0.12 & -0.07 & 0.72 \\
\hline M8 & -0.12 & -0.10 & 0.06 & -0.39 & 0.00 & 0.49 & $0.91 *$ & 0.27 & -0.01 & 0.07 & 0.27 \\
\hline
\end{tabular}

*significantly different from the average of respective components $(\mathrm{p}<0.05)$; **location of field trials: $\mathrm{P}-\mathrm{Priekuli}$, $\mathrm{S}-$ Stende; $* * *$ growing conditions: $\mathrm{O}$ - organic, $\mathrm{C}$ - conventional.

prove to be more significant. However, this theory is not supported by findings of another research, which tested two and three-component mixtures in eight locations (five $\mathrm{O}$ and three $\mathrm{C}$ ), and only in one O location two-component mixtures out-yielded the three-component ones (Kaut et al., 2009). Mille et al. (2006) also reported that under C growing conditions a larger yield increase was observed in three to five-component mixtures, but not in twocomponent mixtures. Similarly, in the present research three-component mixtures M1 and M8 showed a tendency to produce more yield, particularly under C conditions, where in five out of six environments they out-yielded the component average by $5-11 \%$ and $2-13 \%$, respectively, while other three-component mixtures M2 and M3 out-yielded the average in four out of six $\mathrm{C}$ environments. In contrast to what Mille et al. (2006) found about five-component mixtures, in the present study five-component mixture M4 did not perform better than the average of components in most of the environments. However, the number of components is a secondary factor after the yield potential of component genotypes.

\section{Yield of mixtures in comparison to check varieties}

Reports differ on the matter of comparing yields produced by mixtures and pure stand variety. There are results of investigation showing yield increase in mixtures by $13-14 \%$ if compared to varieties in pure stand (Essah \& Stoskop, 2002), as well as results of testing the same mixtures in different environments, showing a yield increase in some of the environments and no increase in others (Tratwal et al., 2007; Kiær, Skovgaard, \& Østergård, 2012). In the present research, the yield of mixtures did not significantly differ if compared to the check varieties in 2015, however, in most cases, in $\mathrm{O}$ and $\mathrm{C}$ farming systems, mixtures slightly out-yielded the check varieties, by $3-29 \%$ and $1-19 \%$, respectively (Figure 1). The largest increase of yield in 2015 was observed for mixture M7 (15 - 29\% and $11-19 \%$ under $\mathrm{O}$ and $\mathrm{C}$ growing conditions, respectively). In 2016 under O growing conditions, mixtures had insignificantly more yield than check varieties 'Abava' and 'Rasa' (by 1 $20 \%$ ), but slightly lower yield than 'Rubiola', while under $\mathrm{C}$ growing conditions the mixture yield was significantly $(\mathrm{p}<0.05)$ higher than check varieties with the lowest yield, but slightly lower $(2-12 \%)$ than that of the check with the highest yield 'Rubiola' (Figure 1). Juskiw et al. (2001) reported similar results: mixtures gave significantly higher yields than the lowest yielding pure stand variety, while no mixture had a higher yield than the highest yielding pure stand.

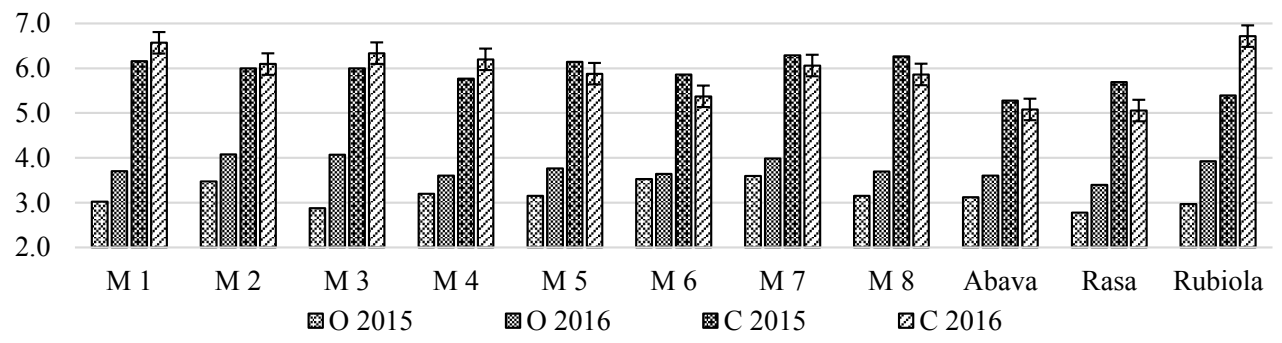

Figure 1. Average yield over organic $(\mathrm{O})$ and conventional $(\mathrm{C})$ environments of mixtures and check varieties, $\mathrm{t} \mathrm{ha}^{-1}, 2015-2016$. 
Average yield of mixtures and its components over 11 environments and yield stability indicators

\begin{tabular}{|c|c|c|c|c|c|c|c|}
\hline Mixture & $\begin{array}{l}\text { Average } \\
\text { yield, } \\
\text { t ha }^{-1}\end{array}$ & $\begin{array}{l}\text { Coefficient of } \\
\text { regression } \\
\text { (b) }\end{array}$ & $\begin{array}{l}\text { Deviation from } \\
\text { regression } \\
\left(s^{2} d j\right)\end{array}$ & $\begin{array}{l}\text { Components } \\
\text { of mixtures }\end{array}$ & $\begin{array}{l}\text { Average } \\
\text { yield, } \\
\text { t ha }^{-1}\end{array}$ & $\begin{array}{l}\text { Coefficient of } \\
\text { regression } \\
\text { (b) }\end{array}$ & $\begin{array}{l}\text { Deviation from } \\
\text { regression } \\
\left(\mathrm{s}^{2} \mathrm{dj}\right)\end{array}$ \\
\hline \multirow{3}{*}{ M 1} & \multirow{3}{*}{4.75} & \multirow{3}{*}{$1.13^{*}$} & \multirow{3}{*}{0.05} & Rubiola & 4.73 & $1.15^{*}$ & 0.16 \\
\hline & & & & BZ14-12 & 4.35 & $0.80^{*}$ & 0.14 \\
\hline & & & & PR-3605 & 4.80 & 1.07 & 0.06 \\
\hline \multirow{3}{*}{ M 2} & \multirow{3}{*}{4.75} & \multirow{3}{*}{1.02} & \multirow{3}{*}{0.05} & Vienna & $4.93 * *$ & 1.12 & 0.14 \\
\hline & & & & PR-5105 & 4.49 & 0.94 & 0.16 \\
\hline & & & & PR-4814 & 4.61 & 1.02 & 0.10 \\
\hline \multirow{3}{*}{ M 3} & \multirow{3}{*}{4.79} & \multirow{3}{*}{1.07} & \multirow{3}{*}{0.09} & Rubiola & 4.73 & 1.15 & 0.16 \\
\hline & & & & Anni & 4.70 & 1.03 & 0.04 \\
\hline & & & & PR-4181 & 4.88 & $1.19^{*}$ & 0.07 \\
\hline \multirow{5}{*}{ M 4} & \multirow{5}{*}{4.59} & \multirow{5}{*}{1.03} & \multirow{5}{*}{0.04} & Vienna & $4.93 * *$ & 1.12 & 0.14 \\
\hline & & & & KZ14-52 & $4.13^{* *}$ & $0.76^{*}$ & 0.08 \\
\hline & & & & PR-3605 & 4.80 & 1.07 & 0.06 \\
\hline & & & & PR-4812 & 4.41 & 1.05 & 0.13 \\
\hline & & & & PR-5135 & 4.71 & 0.98 & 0.06 \\
\hline \multirow{2}{*}{ M 5} & \multirow{2}{*}{4.72} & \multirow{2}{*}{1.03} & \multirow{2}{*}{0.05} & PR-3605 & 4.80 & 1.07 & 0.06 \\
\hline & & & & PR-5105 & 4.49 & 0.94 & 0.16 \\
\hline \multirow{3}{*}{ M 6} & \multirow{3}{*}{4.45} & \multirow{3}{*}{$0.82 *$} & \multirow{3}{*}{0.07} & PR-5330 & 4.55 & 1.02 & 0.10 \\
\hline & & & & PR-4311 & 4.48 & 0.92 & 0.14 \\
\hline & & & & PR-5279 & $4.24 * *$ & $0.77 *$ & 0.09 \\
\hline \multirow{2}{*}{ M 7} & \multirow{2}{*}{4.79} & \multirow{2}{*}{1.03} & \multirow{2}{*}{0.06} & PR-5279 & 4.24 & $0.77^{*}$ & 0.09 \\
\hline & & & & PR-5602 & 4.69 & $1.13^{*}$ & 0.09 \\
\hline \multirow{3}{*}{ M 8} & \multirow{3}{*}{4.60} & \multirow{3}{*}{1.02} & \multirow{3}{*}{0.12} & PR-5279 & $4.24 * *$ & $0.77^{*}$ & 0.09 \\
\hline & & & & PR-5602 & 4.69 & $1.13^{*}$ & 0.09 \\
\hline & & & & PR-6246 & 4.40 & 0.87 & 0.12 \\
\hline
\end{tabular}

*significantly different from $1(\mathrm{p}<0.05)$; ** significantly distinctive from average yield over 11 environments $(\mathrm{p}<0.05)$ $\left(\mathrm{LSD}_{0.05}=0.29\right)$

\section{Yield stability of variety mixtures}

Kiær et al. (2012) reports that spring barley variety mixtures were observed to have a better adaptability to environment than components of mixtures in pure stand. Similar results were reported in studies conducted with other species, such as winter wheat (Cowager \& Weisz, 2008) and spring wheat (Kaut et al., 2009; Zhou et al., 2014). Six out of eight mixtures tested in the present study can be characterized as suitable to different growing conditions or with wide adaptability to environments since their coefficient of regression does not significantly differ from 1 , including mixtures M2, M3, M5 and M7 with an average yield over 11 environments above the average of all genotypes (4.61 t ha $\mathrm{h}^{-1}$ ), and M4 and M8 with equal yield to the average (Table 4). The mixture M1 can be described as suitable to high yielding environments with $b$ significantly above, and its average yield was also higher than the average of the trial, but M6 showed adaptability to low yielding environments, however, its yield was lower than average yield of the trial.

Mixtures M1 and M2 were composed with the aim to test whether it is possible to stabilize the yield by combining genotypes with different adaptability (Table 1). The characterization of mixture M1 components in regard to yield stability was confirmed also in this research (Table 4). As a result, by combining genotypes with different adaptability to growing conditions, a mixture suitable to high yielding environments was derived with a yield that was above the average. Characteristics of M2 components according to results of this study slightly differ from the information available during composing the mixture. The component, which was characterized as suitable to low yielding environments, now is described as having a wide adaptability and maintaining a tendency to adaptability to low yielding environments $(b=0.94)$. 
But the component which was characterized as suitable to high yielding environments, following present study, can be characterized to have wide adaptability, with a tendency towards adaptability to high yielding environments $(b=1.12)$. As a result, similarly to its components, the mixture M2 is characterized by wide adaptability with $\mathrm{b}$ closest to 1 . The genotypes included in the other mixtures were selected without taking into account the component yield stability. Mixture M7 should be highlighted while comparing the yield of mixtures to the component average. Having evaluated the yield stability, we concluded that one of the components of this mixture has a weak suitability to any environment and yield significantly lower than average, while the other is suitable to high yielding environments (Table 4). The mixture M7 composed from these different genotypes can be described as suitable to various growing conditions and its yield was above the average. Our observation confirmed conclusions of another research, that some genotypes have better yield performance growing in mixtures than in pure stand (Juskiw, Helm, \& Salmon, 2000). Similar effect has been observed in the M8 consisting of the same two genotypes used in M7 and the third one, yield of which was slightly above the average. This mixture had been able to provide yield of average level. Mille et al. (2006) reports that the best yielding genotype in pure stand was not the best contributor to the mixtures and inclusion of it in a mixture may not have led to overall yield advantage. In our study, the mixtures, which include the best yielding genotype 'Vienna', were M2 and M4. As mentioned above, M2 was characterized by wide adaptability and yield above the average, whereas five-component mixture M4 consisted of three genotypes which out-yielded average and two components which had lower yield than average. The yield of this mixture was just at the average level, which in this case may support the findings that better yielding genotypes are not the best contributors in mixture.

Assessing mixture yield stability with the rank evaluation method in both $\mathrm{C}$ and $\mathrm{O}$ growing environments M7 ranked either in the top of the list or in the middle (data are not shown in this paper), which corresponds to the previous findings regarding this mixture's adaptability to different growing conditions and yield level above the average. Method of ranking confirmed also the characterization of M1: in $\mathrm{C}$ environments in most cases it was ranked in the top third of the genotype list, which complies with the previously mentioned regarding this mixture's adaptability to favourable growing conditions.

The check varieties used in the study can be characterized as diverse regarding their adaptability: 'Rubiola' - with adaptability to high yielding environments $(\mathrm{b}=1.11)$, 'Rasa' $\quad$ - with wide adaptability $(b=0.92)$ and 'Abava' - with adaptability to low yielding environments $(b=0.78)$ according to data from seven environments; in addition, two of them - 'Rasa' and 'Abava' - had lower yield than average $\left(4.87 \mathrm{tha}^{\mathrm{l}}\right)$. All of the tested mixtures showed better yield performance than 'Rasa' and 'Abava' (data in seven environments are not shown). The third check variety 'Rubiola' out-yielded average over the trial. Three out of eight mixtures - M1, M2 and M7 out-yielded this variety, M3 yielded the same as 'Rubiola' and other mixtures had slightly lower yield.

\section{Conclusions}

1. Three mixtures, each in one out of 11 environments significantly out-yielded, but one mixture had significantly lower yield than the average value of their components in pure stand. Two-component mixture M7 out-yielded the component average in eight out of eleven testing environments by $1-15 \%$.

2. To evaluate performance of genotype mixtures in comparison to check varieties in 2015 under both growing conditions and 2016 under organic conditions, yield increase by $1-29 \%$ was observed, but in 2016 under conventional growing conditions mixtures significantly out-yielded check varieties with the lowest yield 'Abava' and 'Rasa', but had a slightly lower yield than highest yielding variety 'Rubiola'.

3. The results of yield stability showed that genotype mixtures could be used as one of approaches to stabilize yield: six out eight mixtures can be characterized as suitable to different growing conditions; all mixtures were more stable with higher average yield than check varieties 'Rasa' and 'Abava'; three mixtures were more stable and with a higher average yield than 'Rubiola'.

\section{Acknowledgements}

Financial support for this study was provided by the Latvian Council of Science project Nr. 155/2012 "Genetically diverse varieties for environmentally friendly agriculture - study on advantages and breeding strategies".

\section{References}

1. Askegaard, M., Thomsen, I.K., Berntsen, J., Hovmøller, M.S., \& Kristensen, K. (2011). Performance of spring barley varieties and variety mixtures as affected by manure application and their order in an organic crop rotation. Acta Agriculture Scandinavica Section B - Soil and Plant Science, 61, 421 - 430. DOI: 10.1080/09064710.2010.501340. 
2. Cowger, C., \& Weisz, R. (2008). Winter wheat blends (mixtures) produce a yield advantage in North Carolina. Agronomy Journal, 100(1), 169 - 177. DOI: 10.2134/agronj2007.0128.

3. Döring, T.F., Knapp, S., Kovacs, G., Murphy, K., \& Wolfe, M.S. (2011). Evolutionary plant breeding in cereals-into a new era. Sustainability, 3(10), 1944 - 1971. DOI: 10.3390/su3101944.

4. Eberhart, S.A., Russel, W.A. (1966). Stability parametrs for comparing varieties. Crop Science, 6(1), 36 40. DOI: $10.2135 /$ cropsci1966.0011183X000600010011x.

5. Essah, S.Y.C., \& Stoskopf, N.C. (2002). Mixture performance of phenotypically contrasting barley cultivars. Canadian Journal of Plant Science, 82, 1 - 6. DOI: 10.4141/P01-043.

6. Fess, T.L., Kotchon, B.J., Beneditto, A.V. (2011). Crop breeding for low input agriculture: A sustainable response to feed a growing world population. Sustainability, 3, $1742-1772$. DOI: 10.3390/su3101742.

7. Fox, P.N., Skovmand, B., Thompson, B.K., Braun, H.J., \& Cormier, R. (1990). Yield and adaptation of hexaploid spring triticale. Euphytica, 47(1), 57 - 64. DOI: 10.1007/BF00040364.

8. Jedel, P.E., Helm, J.H., \& Burnett, P.A. (1998). Yield, quality and stress tolerance of barley mixtures in central Alberta. Canadian Journal of Plant Science, 78, 429 - 436. DOI: 10.4141/p97-137.

9. Juskiw, P.E., Helm, J.H., \& Burnett, P.A. (2001). Three-component barley mixtures: Ratio effects in replacement series. Canadian Journal of Plant Science, 81(4), 651 - 656. DOI: 10.4141/P00-145.

10. Juskiw, P.E., Helm, J.H., \& Salmon, D.F. (2000). Competitive ability in mixtures of small grain cereals. Crop Science, 40, 159 - 164. DOI: 10.2135/cropsi2000.401159x.

11. Kārkliňš, A. (2008). Augsnes diagnostika un apraksts (Guidelines for soil diagnosis and description). Jelgava: LLU. (in Latvian).

12. Kaut, A.H.E.E., Mason, H.E., Navabi, A., O’Donovan, J.T., \& Spaner, D. (2009). Performance and stability of performance of spring wheat variety mixtures in organic and conventional management systems in western Canada. Journal of Agricultural Science, 147(2), 141 - 143. DOI: 10.1017/S0021859608008319.

13. Kiær, L.P., Skovgaard, I.M., \& Østergård, H. (2012). Effects of inter-varietal diversity, biotic stresses and environmental productivity on grain yield of spring barley variety mixtures. Euphytica, 185(1), $123-138$. DOI: 10.1007/s10681-012-0640-1.

14. Lopez, C.G., \& Mundt, C.C. (2000). Using mixing ability analysis from two-way cultivar mixtures to predict the performance of cultivars in complex mixtures. Field Crop Research, 68(2), 121 - 132. DOI: 10.1016/S0378-4290(00)00114-3.

15. Mille, B., Belhaj Fraj, M., Monod, H., \& De Vallavieille-Pope, C. (2006). Assessing four-way mixtures of winter wheat cultivars from the performances of their two-way and individual components. European Journal of Plant Pathology, 114(2), 163 - 173. DOI: 10.1007/s10658-005-4036-0.

16. Muchova, D., \& Fazekašova, D. (2010). The contribution of variety mixture utilization for enhancing the resilience of agro-ecosystems. In Proceedings of the $9^{\text {th }}$ Alps-Adria Scientific Workshop, $12-17$ April 2010 (pp. 509 - 512). Budapest, Hungry: Akadèmiai Kiadò.

17. Newton, A.C., Guy, D.C. (2009). The effects of uneven, patchy cultivar mixtures on control and yield in winter barley. Field Crops Research, 110(3), 225 - 228. DOI: 10.1016/j.fcr.2008.09.002.

18. Newton, A.C., Guy, D.C., Bengough, A.G., Gordon, D.C., McKenzie, B.M., Sun, B., ... Hallett, P.D. (2012). Soil tillage effects on the efficacy of cultivars and their mixtures in winter barley. Field Crops Research, 128, 91 - 100. DOI: 10.1016/j.fcr.2011.12.004.

19. Newton, A.C., Hackett, C.A., \& Swanson, J.S. (2008). Analysing the contribution of component cultivars and cultivar combinations to malting quality, yield and disease in complex mixtures. Journal of the Science of Food and Agriculture, 88, 2142 - 2152. DOI: 10.1002/jsfa.3326.

20. Petersen, R.G. (1994). Agricultural Field Experiments. New York: Marcel Dekker.

21. Tratwal, A., Law, J., \& Philpott, H. (2007). The Possibilities of Reduction of Winter Barley Chemical Protection By Growing Variety Mixtures. Part I. Effect on Powdery Mildew level. Journal of Plant Protection Research, 47(1), $65-77$.

22. Tratwal, A., Law, J., Philpott, H., Horwell, A., \& Garner, J. (2007). The possibilities of reduction of winter barley chemical protection by growing variety mixtures. Part II. Effect on yield. Journal of Plant Protection Research, 47(1), $79-86$.

23. Wolfe, M.S., Baresel, J.P., Desclaux, D., Goldringer, I., Hoad, S., Kovacs, G., ... Lammerts Van Bueren, E.T. (2008). Developments in breeding cereals for organic agriculture. Euphytica, 163(3), 323 - 346. DOI: 10.1007/s10681-008-9690-9.

24. Zhou, K.Q., Wang, G.D., Li, Y.H., Liu, X.B., Herbert, S.J., \& Hashemi, M. (2014). Assessing variety mixture of continuous spring wheat (Triticum aestivum L.) on grain yield and flour quality in Northeast China. International Journal of Plant Production, 8(1), 91 - 105. DOI: 10.22069/ijpp.2014.1374. 